\begin{tabular}{|c|c|c|}
\hline \multirow{2}{*}{$\begin{array}{l}\text { Cellular Physiology } \\
\text { and Biochemistry }\end{array}$} & \multicolumn{2}{|c|}{ Cell Physiol Biochem 2018;47:505-522 } \\
\hline & $\begin{array}{l}\text { DOI: 10.1159/000489984 } \\
\text { Published online: May 24, } 2018 \\
\text { Accepted: March 13, } 2018\end{array}$ & $\begin{array}{l}\text { (c) } 2018 \text { The Author(s) } \\
\text { Published by S. Karger AG, Basel } \\
\text { www.karger.com/cpb }\end{array}$ \\
\hline
\end{tabular}

\title{
Long Noncoding RNA Profiling from Fasciola Gigantica Excretory/Secretory Product-Induced M2 to M1 Macrophage Polarization
}

\author{
Honglin Luo ab,e,f Yaoyao Zhang ${ }^{c}$ Zhaoan Sheng ${ }^{c}$ Tao Luo ${ }^{a, e, f} \quad J i e C^{a}{ }^{a, e, f}$ \\ Junjie Liud,f Huifeng Wang ${ }^{\mathrm{a}, \mathrm{e}, \mathrm{f}}$ Miao Chen ${ }^{\mathrm{d}, f}$ Yunliang Shi ${ }^{g}$ Lequn Li $i^{\mathrm{a}, \mathrm{e}, \mathrm{f}}$ \\ aDepartment of Hepatobiliary Surgery, Affiliated Tumor Hospital of Guangxi Medical University, \\ Nanning, ${ }^{b}$ Guangxi Key Laboratory for Aquatic Genetic Breeding and Healthy Aquaculture, Guangxi \\ Institute of Fishery Sciences, Nanning, 'Institute of Animal Science and Technology, Guangxi University, \\ Nanning, dDepartment of Ultrasound, Affiliated Tumor Hospital of Guangxi Medical University, \\ Nanning, ${ }^{e}$ Key Laboratory of High-Incidence-Tumor early Prevention and Treatment, Ministry of \\ Education, Nanning, ${ }^{f}$ Guangxi Medical University, Nanning, Institute of parasitic disease prevention \\ and control, Guangxi Zhuang Autonomous Region Center for Disease Control and Prevention, \\ Nanning, China
}

\section{Key Words}

Long non-coding RNA • Fasciola gigantica - Macrophage polarization • Excretory /secretory products $(\mathrm{ESP}) \cdot \mathrm{CeRNA}$

\begin{abstract}
Background/Aims: Long noncoding RNAs (IncRNAs) are well known regulators of gene expression that play essential roles in macrophage activation and polarization. However, the role of IncRNA in Fasciola gigantica excretory/secretory products (ESP)-induced M2 polarization into M1 macrophages is unclear. Herein, we performed IncRNA profiling of IncRNAs and mRNAs during the ESP-induced macrophage polarization process. Methods: F. gigantica ESP was used to induce peritoneal cavity M2 macrophages in BALB/C mice (5-6 weeks old) in vivo, and these cells were subsequently isolated and stimulated with IFN- $\gamma+$ LPS to induce M1 cells in vitro. LncRNA and mRNA profiling was performed via microarray at the end of both polarization stages. Results: In total, 2,844 IncRNAs (1,579 upregulated and 1,265 downregulated) and 1,782 mRNAs (789 upregulated and 993 downregulated) were differentially expressed in M2 macrophages compared to M1 macrophages, and six IncRNAs were identified during polarization. We selected 34 differentially expressed IncRNAs and mRNAs to validate the results of microarray analysis using quantitative real-time PCR (qPCR). Pathway and Gene Ontology (GO) analyses demonstrated that these altered transcripts were involved in multiple biological processes, particularly peptidase activity and carbohydrate metabolism.
\end{abstract}

H. Luo, Y. Zhang and Z. Sheng contributed equally to this work.

Lequn $\mathrm{Li}$

and Honglin Luo

KARGER
Department of Hepatobiliary Surgery, Affiliated Tumor Hospital of Guangxi Medical University Nanning 530021 (China)

Tel. +86 771 5316334, E-Mail Ihl200296@aliyun.com, li_lequn@163.net 
Furthermore, coding and non-coding gene (CNC) and mRNA-related ceRNA network analyses were conducted to predict IncRNA expression trends and the potential target genes of these IncRNAs and mRNAs. Moreover, we determined that four IncRNAs and four mRNAs might participate in $F$. gigantica ESP-induced M2 polarization into M1 macrophages. Conclusions: This study illustrates the basic profiling of IncRNAs and mRNAs during F. gigantica ESP-induced M2 polarization into M1 macrophages and deepens our understanding of the mechanism underlying this process.

(C) 2018 The Author(s)

Published by S. Karger AG, Basel

\section{Introduction}

Macrophages play a central role in inflammation and host defense. In response to tissue microenvironmental signals, macrophages activate and differentiate into diverse phenotypes as required. Classically activated macrophages (M1 cells) induced by IFN $-\gamma /$ LPS secrete high levels of IL-12, IL-23, IL-6, TNF- $\alpha$, and iNOS, but low levels of IL-10, thereby promoting Th1type inflammatory responses $[1,2]$. In contrast, alternatively activated macrophages (M2 cells) induced by IL-4/IL-13 express high levels of IL-10, YM-1, arginase-1, and RELM $\alpha$, but low levels of IL-12 to promote Th2-type responses, wound healing, and inflammation resolution $[3,4]$. The helminth can survive within its hosts due to its ability to manipulate host immunity, in particular the suppression of Th1 immune responses which is correlated with immune protection in the host. Helminth infection induces a polarized Th2 response characterized by an increase of IL-4, IL-5, and IL-13, but a decrease in IFN $\gamma$ [5]. Like other helminths, $F$. hepatica infection and its excretory/secretory products (ESP) inhibit the development of M1 which facilitates the switch to the M2 phenotype, and modulates the host immune response by inducing potent polarized M2 (Th2) and by downregulating the production of M1 (Th1) macrophages [6, 7]. Fascioliasis, which is caused by F hepatica or F. gigantica afflicts at least 2.6 million people around the world $[8,9]$, causes hepatic pathologies such as liver fibrosis, cirrhosis, and even cancer [10]. Moreover, fascioliasis outbreaks caused by F. gigantica in Yunnan, China further suggested that this pathogen might be zoonotic [11]. Therefore, decoding the biological and immunological feature of $F$. gigantica is imperative for public health. Though few reports have shown that Fgigantica could induce M1 or M2 phenotype, our preliminary experimental results suggested that F.gigantica was capable of inducing strong M2 and weak M1 phenotype during infection of water buffalo and mice (unpublished). This observation suggested that Fgigantica infection can induce M1/M2 mixed macrophages skewed towards an M2 phenotype, and might induce macrophage phenotypes similar to F. hepatica. Since M1 and M2 represent two different major immune responses (Th1 and Th2 response, respectively), we hypothesized that $\mathrm{t}$ different immunomodulatory molecules play varying roles following F.gigantica infection. Specifically in F. gigantica ESP proteins, we identified 297 proteins, including 118 cytosol proteins, 22 nuclear proteins, 59 mitochondria proteins, 3 endoplasmic reticulum, 1 peroxisome, 3 cytosol and mitochondria proteins, 9 cytoskeleton proteins, 52 extracellular proteins, 7 plasma membrane proteins, and 23 cytosol and nuclear proteins (unpublished). We also found that heat shock protein 70, cathepsin B-like peptidase and thioredoxinglutathione reductase might play key roles on the immune cell differentiation. Thus, the objective of our present study was to identify potential lncRNAs and mRNAs that might be novel targets for preventive, diagnostic or therapeutic strategies against fasciola infections. We posit that the identification of molecular targets that can regulate the M1 and M2 switch will spur strategies that can lead to early diagnosis, prevention or control $F$. gigantica infections. Moreover, elucidating the mechanism underlying macrophage polarization from the M2 to M1 subtypes during F. gigantica infection may provide insights into illuminating the mechanisms underlying helminth ESP-induced macrophage polarization.

Long non-coding RNAs (lncRNAs) are key regulators with diverse roles in various biological processes $[12,13]$. Studies have shown that IncRNAs play essential roles in macrophage polarization and activation. For example, lnc-MC regulates polarization of 
human mononuclear macrophages via absorption of miR-199a-5p [14], and overexpression of IncRNA E330013P06 induces inflammatory gene expression and enhances inflammatory signaling pathways [15]. In addition, TCONS_00019715 promotes macrophage polarization to the M1 phenotype [16]. However, whether IncRNAs play regulatory roles in helminth ESPinduced macrophage polarization remains unclear. To address this hypothesis, an lncRNA microarray-based assay was employed to identify the differentially expressed lncRNAs between $F$ gigantica ESP induced-M2 phenotype and IFN- $\gamma+$ LPS-induced M1 phenotype. Our data showed that the expression of various IncRNAs and mRNAs consistently changed, and important biological processes and essential signaling pathways, were identified during polarization. These findings suggest that lncRNAs are important regulators of helminth ESPinduced macrophage polarization.

\section{Materials and Methods}

\section{Ethics statement}

This study was performed in accordance with the Guide for Care and Use of Laboratory Animals of the National Institutes of Health. The protocol was approved by the Ethics and Animal Welfare Committee of the Guangxi Institute of Fishery Sciences.

\section{Preparation of F. gigantica ESP}

All animal experimental procedures were performed according to the International Guiding Principles for Biomedical Research Involving Animals as documented by the International Organizations of Medical Sciences. The preparation of F. gigantica ESP was performed as described by El Ridi et al [39]. with the exception that the F gigantica adults were obtained from infected water buffalo instead of sheep. Concentrations of ESPs were tested and stored $-80^{\circ} \mathrm{C}$.

\section{F. gigantica ESP-induced M2 cell purification and culture}

BALB/c mice (5-6 weeks old) were intraperitoneally injected with $0.1 \mathrm{mg}$ F. gigantica ESP per mice at two days interval. The peritoneal cavity macrophages were isolated and collected at 1, 2, and 3 weeks after the first injection by density gradient centrifugation on Ficoll-Paque (Sigma-Aldrich, USA). Mice injected with PBS were used as controls. The purified macrophages were cultured in RPMI1640 medium containing $10 \%$ FBS and $0.05 \%$ glutamine (Sigma) for $48 \mathrm{~h}$ at $5 \% \mathrm{CO}_{2}$ and $37{ }^{\circ} \mathrm{C}$ [40], then the cells were collected for RNA isolation. M2 macrophage phenotype was identified by qPCR by using M2 macrophage molecule marker YM-1, arginase-1, and RELM $\alpha$ specific primers (Table 3).

\section{M1 macrophage polarization}

To induce M1 macrophage polarization, the identified F. gigantica ESP-induced M2 macrophages were treated with $10 \mathrm{ng} / \mathrm{mL}$ of IFN- $\gamma$ (R\&D Systems, USA) and $50 \mathrm{ng} / \mathrm{mL}$ of LPS (Sigma). After $24 \mathrm{~h}$ of polarization, the cells were collected for RNA isolation and M1 macrophage phenotype was identified by qPCR by using M1 macrophage molecule marker iNOS-specific primer (Table 3).

qPCR

Purified total RNA was reverse-transcribed by using the PrimeScript RT reagent (Takara, Japan). The expression pattern of selected IncRNAs and mRNA correlating with ESP-induced macrophage polarization were measured.qPCR was performed on ABI 7500 PCR instrument using SYBR green reagents (Life Technologies, Carlsbad, CA, USA) following the manufacturer's protocol. The specific primer sequences are listed in Table 3. All qPCR experiments were performed in triplicate. The expression levels of RNA were normalized to internal control $\beta$-actin, and calculated with ${ }^{\Delta} \mathrm{CT}$ method.

Western blotting assay

Samples were mixed with loading mix (Sample Reducing Agent; NuPAGE), denatured and resolved by SDS-PAGE, using pre-cast 4-12\% NuPAGE gel followed by transfer onto nitrocellulose filter (BioRad Trans Blot) for Western blotting by electrophoresis at 30 volts for $1 \mathrm{~h}$. Membranes were washed with 1xTBS and 


\begin{tabular}{|c|c|c|}
\hline Cellular Physiology & Cell Physiol Biochem 2018; & 17:505-522 \\
\hline and Biochemistry & $\begin{array}{l}\text { DOI: 10.1159/000489984 } \\
\text { Publisnec online: : May 24, } 2018\end{array}$ & $\begin{array}{l}\text { O } 2018 \text { The Author(s). Published by S. Karger AG, Basel } \\
\text { www.karger.com/cpb }\end{array}$ \\
\hline
\end{tabular}

Table 1. Top 15 differentially expressed IncRNAs and corresponding coding RNA

\begin{tabular}{|c|c|c|c|c|c|c|c|}
\hline No & Seqname & Coding Cene & Fold change & 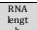 & Reatitionship & R.value & \\
\hline 1 & uc020evd1 & Pekhas & 1.8282261 & $\frac{n}{1074}$ & exon sense-veralapping & 0.02266717 & \\
\hline 2 & АКо089651 & АК АК 09651 & 5.8302576 & 2688 & Intronic antisense & $\begin{array}{l}0.0437345 \\
19\end{array}$ & \\
\hline 3 & AK1 13149 & AK 134149 & 5.4447724 & 1461 & natural antisense & $\begin{array}{l}0.0268267 \\
81\end{array}$ & \\
\hline 4 & uс007gex & АКовз306 & 5.1287667 & 3520 & intergenic & $\begin{array}{c}0.0169856 \\
9\end{array}$ & \\
\hline 5 & ENSMUSTrooooo0133801 & Aspdh & 4.8486616 & вв9 & exon sense-overhpping & $\begin{array}{l}0.0361825 \\
43\end{array}$ & \\
\hline 6 & ENSMUSTroo0000154000 & Gm13069 & 4.4691894 & 317 & Intronic antisense & $\begin{array}{l}0.0377560 \\
55\end{array}$ & \\
\hline 7 & ENSMUSTrooooo0131267 & Kanb1 & 4.2878054 & 702 & exon sense-over ehpping & $\begin{array}{l}0.0+0000023 \\
98\end{array}$ & \\
\hline 8 & uc008uch.1 1 & AK 148461 & 4.0100251 & 2064 & bidirectional & $\begin{array}{l}0.0351751 \\
99\end{array}$ & $\begin{array}{c}\text { Top } 15 \\
\text { upp. }\end{array}$ \\
\hline 9 & uc007/h.1 & AK016100 & 3.8638325 & 793 & intergenic & 0.0468449 & regulahte \\
\hline${ }_{10}$ & ENSMUSTroo0000142699 & Fam167b & 3.8142052 & 527 & exon sense-overhpping & $\frac{0.0106623}{36}$ & \\
\hline${ }_{11}$ & AK005751 & AKo05751 & 3.5970826 & 692 & intronic antisense & $\begin{array}{l}0.0312759 \\
87\end{array}$ & \\
\hline 12 & ENSMUST000000117368 & Gm13916 & 3.3566363 & ${ }_{628}$ & intergenic & $\begin{array}{l}0.0265817 \\
0.5517\end{array}$ & \\
\hline 13 & Human lincRNA1799+ & $\begin{array}{c}\text { Hu- } \\
\text { IIncRNA1799 }\end{array}$ & 2.9765229 & ${ }^{8248}$ & intergenic & $\begin{array}{l}0.0184289 \\
14\end{array}$ & \\
\hline 14 & ENSMUSTroooo00142279 & Gim11494 & 2.8129311 & 1738 & intergenic & $\begin{array}{l}0.0296844 \\
97\end{array}$ & \\
\hline 15 & EnsMustrooooo0163450 & Tro & 2.6993409 & 888 & exon sense-overhpping & $\begin{array}{l}0.0438254 \\
02\end{array}$ & \\
\hline 16 & AK009651 & АК & 5.8302576 & 2688 & intronic antisense & $\begin{array}{l}0.0437345 \\
19\end{array}$ & \\
\hline 17 & AK1 134149 & AK134149 & 5.4947724 & 1461 & natural antisense & $\begin{array}{l}0.0268267 \\
81\end{array}$ & \\
\hline 18 & uc007gxd1 & AK003306 & 5.1287667 & 3520 & intergenic & $\begin{array}{l}0.0109056 \\
0.01056\end{array}$ & \\
\hline 19 & ENSMUSTrooooo0 133801 & Aspdh & 4.8448616 & 889 & exon sense-overapping & $\begin{array}{l}0.03631825 \\
43\end{array}$ & \\
\hline 20 & ENSMUSTroooo00154000 & Gm13069 & 4.4691894 & 317 & Intronic antisense & $\begin{array}{l}0.0337560 \\
0.3560\end{array}$ & \\
\hline 21 & ENSMUSTrooooo0131267 & Kanb1 & 4.2878054 & 702 & exon sense-over ehpping & $\begin{array}{l}0.04000023 \\
98\end{array}$ & \\
\hline 22 & uc0obuch.1 & AK148461 & 4.0100251 & 2064 & bldirectional & $\begin{array}{l}0.0351751 \\
99\end{array}$ & Top 15 \\
\hline 23 & uc007ib. 1 & АK016100 & 3.8638325 & 793 & intergenic & $\begin{array}{l}0.0466449 \\
75\end{array}$ & $\begin{array}{c}\text { Down- } \\
\text { regulate }\end{array}$ \\
\hline 24 & ENSMUSTroo000 142699 & Fam167s & 3.8142052 & 527 & exon sense-overhpping & $\begin{array}{l}0.0160623 \\
36\end{array}$ & thal \\
\hline 25 & AK005751 & AKo05751 & 3.5970826 & 692 & intronic antisense & $\begin{array}{l}0.036 \text { 12759 } \\
0.575\end{array}$ & \\
\hline 26 & ENSMUST000000117368 & Gm13916 & 3.3566363 & 628 & intergenic & $\begin{array}{l}0.0265817 \\
{ }_{95}\end{array}$ & \\
\hline 27 & human nlineRNA1799+ & 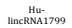 & 2.9765229 & 8248 & intergenic & $\begin{array}{l}0.0984289 \\
14\end{array}$ & \\
\hline 28 & ENSMUSTroo000142279 & Gm11494 & 2.8129311 & 1738 & intergenic & $\begin{array}{l}0.02968644 \\
97\end{array}$ & \\
\hline 29 & ENSMUSTroooo00163450 & tro & 2.6993409 & 888 & exon sense-overapping & $\begin{array}{l}0.0438254 \\
0254\end{array}$ & \\
\hline 30 & TCONS 00025154 & XL.0C, 018794 & 26048995 & 225 & intergenic & 0.0170768 & \\
\hline
\end{tabular}

then incubated for $1 \mathrm{~h}$ in 5\% skim milk in TBS. Primary antibodies Anti-YM1 (1/1000) and Anti-iNOS (1/500) were then incubated with the blots overnight at $4^{\circ} \mathrm{C}$. $\beta$-actin (1:200, Abcam, UK) was used as control. Incubation with Goat-anti-Rabbit IgG- HRP: $1 / 1000$ for $1 \mathrm{~h}$ was followed with detection by enhanced chemiluminescence method according to the manufacturer's protocol (ECL kit; Amersham).

Table 2. Top 15 differentially expressed mRNA

\begin{tabular}{|c|c|c|c|c|c|c|}
\hline No. & Seq name & Gene Symbol & Fold Change & RNA length & $\mathrm{P}$-value & \multirow{15}{*}{$\begin{array}{c}\text { Top } 15 \\
\text { Up-regulated }\end{array}$} \\
\hline 1 & NM_001159497 & Ppm1b & 6.6124735 & 1609 & 0.031609609 & \\
\hline 2 & NM_134173 & Vmn1r24 & 3.6058195 & 891 & 0.022019815 & \\
\hline 3 & NM_009063 & Rgs5 & 3.4941021 & 1809 & 0.024945756 & \\
\hline 4 & NM_021307 & Zfp112 & 3.2544098 & 3507 & 0.024820576 & \\
\hline 5 & NM_001272045 & Ces2h & 3.057114 & 1677 & 0.009364195 & \\
\hline 6 & NM_175263 & Notum & 2.928983 & 2020 & 0.01027892 & \\
\hline 7 & NM_147079 & Olfr547 & 2.7983575 & 940 & 0.004879411 & \\
\hline 8 & NM_001113487 & Sept9 & 2.6263821 & 3796 & 0.042643463 & \\
\hline 0 & NM_001177778 & Dlg3 & 2.5646848 & 4958 & 0.024382693 & \\
\hline 10 & NM_027721 & Katnal2 & 2.4535415 & 1673 & 0.049252194 & \\
\hline 11 & NM_198962 & Hcrtr2 & 2.3592752 & 3728 & 0.023600725 & \\
\hline 12 & NM_001135991 & Krtap10-4 & 2.3089433 & 902 & 0.011179904 & \\
\hline & NM_011997 & Casp8ap2 & 2.2716324 & 6805 & 0.049740276 & \\
\hline 14 & NM_029002 & Nkx6-3 & 2.2297996 & 2236 & 0.0231563 & \\
\hline 15 & NM_172873 & Cdcp 2 & 2.1194175 & 2611 & 0.033573453 & \multirow{16}{*}{$\begin{array}{c}\text { Top } 15 \\
\text { Down-regulated }\end{array}$} \\
\hline 16 & NM_009690 & Cd51 & 47.1045255 & 2037 & 0.033771358 & \\
\hline 17 & NM_001025574 & Bpifb9b & 23.9093383 & 2083 & $1.56801 \mathrm{E}-05$ & \\
\hline 18 & NM_174990 & Gimap4 & 20.0433599 & 1814 & 0.031241985 & \\
\hline 19 & NM_018781 & Egr3 & 7.517049 & 1416 & 0.011625404 & \\
\hline 20 & NM_001199224 & Agbl1 & 6.5710109 & 3369 & 0.000778652 & \\
\hline 21 & NM_009638 & Crisp1 & 6.1722717 & 1416 & 0.048338258 & \\
\hline 22 & NM_152839 & Igj & 5.4467555 & 2111 & 0.030702143 & \\
\hline 23 & NM_001039223 & Gm14137 & 5.4000889 & 3067 & 0.02536975 & \\
\hline 24 & NM_016696 & Gpc1 & 4.5873121 & 3552 & 0.003945357 & \\
\hline 25 & NM_009994 & Сyp1b1 & 4.5443241 & 5128 & 0.048170482 & \\
\hline 26 & NM_021985 & Tnfrsf 18 & 4.2782858 & 817 & 0.04512882 & \\
\hline 27 & NM_024245 & Kif23 & 4.0384839 & 3439 & 0.043661422 & \\
\hline 28 & NM_011346 & Sell & 3.8263997 & 2341 & 0.017107466 & \\
\hline 29 & NM_016707 & Bcl11a & 3.516451 & 3425 & 0.012461752 & \\
\hline 30 & NM_001077508 & Tnfrsf9 & 3.5154845 & 1999 & 0.030462784 & \\
\hline
\end{tabular}

\section{ELISA assay}

The expression of cytokines IL-12(p70), and IL-10 in the culture supernatants was measured with ELISA according to the manufacturer's instructions (Invitrogen, UK). Briefly, 96 wells plates were coated at $50 \mu \mathrm{l} /$ well with capture antibody in carbonate buffer and incubated at $4^{\circ} \mathrm{C}$ overnight, followed by incubation in PBS $+4 \%$ BSA $(200 \mu \mathrm{l} /$ well $) 2 \mathrm{~h}$ at room temperature in dark. Then $50 \mu \mathrm{l} /$ well 2 -folds diluted standard (Top concentration: IL10 at $10 \mathrm{ng} / \mathrm{ml}, \mathrm{IL}-12(\mathrm{p} 70)$ at $50 \mathrm{ng} / \mathrm{mg}$ diluted with PBS-BSA 1\%) was added, followed by the addition of $50 \mu \mathrm{l} /$ well samples and incubation at $4{ }^{\circ} \mathrm{C}$ overnight. Plates were then incubated in biotinylated antibody (final solution: IL10 at $2 \mu \mathrm{g} / \mathrm{ml}$, IL-12(p70) at $1 \mu \mathrm{g} / \mathrm{ml}$ ) $1 \mathrm{~h}$ followed by $30 \mathrm{~min}$ incubation in AMDEX streptavidin-peroxidase (Sigma, UK) with dilution 1: 6000 in PBS-1\%BSA. Finally, 50 $\mu \mathrm{l} /$ well TMB (Invitrogen UK) was added and plates were incubated at room temperature. When blue color was intense only in upper standard wells, the reaction was blocked by addition of $20 \mu \mathrm{l} \mathrm{H}_{2} \mathrm{SO}_{4}$ at $1 \mathrm{mM}$. Plates were read at $450 \mathrm{~nm}$.

\section{RNA isolation}

Total RNA of the M1 and M2 macrophages was extracted by using TRIzol reagent (Invitrogen, USA) according to the manufacturer's protocol. The RNA concentration and integrity was evaluated by NanoDrop ND-1000 spectrophotometer and denaturing electrophoresis, respectively. 
Microarray and data analysis

Arraystar mouse LncRNA Microarray v3.0 was designed to globally profile the mouse LncRNAs and protein-coding transcripts. Three paralleled mRNA samples in each group (two groups in total) were purified by using ONLYTM Eukaryotic mRNA Isolation Kit (Epicentre Biotechnologies, USA) after removal of rRNA. A random priming method was used to amplify and transcribe the mRNA into fluorescent cRNA. NanoDrop ND-1000 was used to measure the concentration of the Cy3-labelled cRNAs (pmol Cy3/ $\mu$ g cRNA). The labelled cRNA (1 $\mu$ g per sample) was gently fragmented by adding $5 \mu \mathrm{L} 10 \times$ blocking agent and $1 \mu \mathrm{L}$ of $25 \times$ fragmentation buffer before heating to $60^{\circ} \mathrm{C}(30 \mathrm{~min})$ and diluting with $25 \mu \mathrm{L} 2 \times$ GE hybridization buffer. Next, $50 \mu \mathrm{L}$ of the hybridization solution was added into the gasket slide and aliquoted onto the mouse LncRNA Array v3.0 slide (8x $60 \mathrm{~K}$, Arraystar), followed by an incubation for at $65^{\circ} \mathrm{C}$ in an Agilent hybridization oven for $17 \mathrm{~h}$. The Agilent DNA Microarray Scanner (Agilent p/n G2565BA) was then used to scan the slide after careful washing and fixation. Authoritative databases, such as UCSC mouse (GRCm38/mm10), IncRNAdb (2.0), GENCODE 13, and RefSeq (release 55), were chosen for microarray analysis, and about 35, 666 IncRNAs and 22, 198 coding transcripts were detected. The obtained microarray images analysis and data normalization was performed by Agilent Feature Extraction software (version 11.0.1.1) and GeneSpring GX v12.0 software package (Agilent Technologies), respectively. UCSC Genome Browser was used to identify the protein-coding genes corresponding to the differentially expressed IncRNAs. All microarray analysis was performed by KangChen Bio-tech, Shanghai, China.

\section{Gene Ontology and pathway analyse}

GO and pathway analysis were performed to predict the roles of differentially expressed lncRNAs (DE lncRNAs) in signaling pathways or GO terms. The corresponding target genes of the DE IncRNAs were mapped to GO terms and integrated discovery DAVID program (http://david.abcc.ncifcrf. gov/). True difference between groups was evaluated by Fisher's exact test. The Kyoto Encyclopedia of Genes and Genomes (KEGG,
Table 3. Primer sequences used in present study

\begin{tabular}{|c|c|c|c|}
\hline Gene name & Primers $\left(5^{\prime}\right.$ to $\left.3^{\prime}\right)$ & $\mathrm{Tm}(\mathrm{C})$ & Length (bp) \\
\hline$\beta$-Actin & $\begin{array}{l}\text { For: TGGAATCCTGTGGCATCCATGAAAC } \\
\text { Rev: TAAAACGCAGCTCAGTAACAGTCCG }\end{array}$ & 60 & 384 \\
\hline YM1 & $\begin{array}{l}\text { Fer TCAAGGGTTCGGAAATCTTCTG } \\
\text { Rev:TTGTCCTTAGGAGGCTTCCTC }\end{array}$ & 57 & 435 \\
\hline & For: CAGAAGAATGGAAGAGTCAG & 56 & (2) \\
\hline Arg-1 & Rev: CAGATATGCAGGGAGTCACC & 56 & 249 \\
\hline iNOS & $\begin{array}{l}\text { For: GCATTTGGGAATGTAGACTG } \\
\text { Rev GTTCATTGGAGTGAGCGTTT }\end{array}$ & 59 & 334 \\
\hline RELMa & $\begin{array}{l}\text { For: TATGAACAAATGGGCCTCCT } \\
\text { Rev: GGCAGTTGCAAGTATCTCCAC }\end{array}$ & 59 & 107 \\
\hline Ch25 & $\begin{array}{l}\text { For: : GTCGTCCCAGCTCCTAAGTC } \\
\text { Rev AGCACGTGAGAAGTCAG }\end{array}$ & 56 & 204 \\
\hline Olfr1512 & $\begin{array}{l}\text { For: CTCTCCGTCATCGACATGGG } \\
\text { Rev: GTGGTGTATAGGAACACTGGGA }\end{array}$ & 57 & 155 \\
\hline Arhgap15 & $\begin{array}{l}\text { For: GTGGTGTATAGGAAACACTGGGA } \\
\text { Rev: TGGAGAAAAGGACAAGCTGC }\end{array}$ & 60 & 210 \\
\hline Shh & $\begin{array}{l}\text { For: TCGAAACCCAACTCCGATGT } \\
\text { Rev: TATATAACCTTGCCTGCCGCT }\end{array}$ & 58 & 117 \\
\hline Uspl1 & $\begin{array}{l}\text { For: GAAGGAGCGTACTTCGGGAG } \\
\text { Rev: CATCAGTCCCTGGTCCAACC }\end{array}$ & 57 & 149 \\
\hline Bard1 & $\begin{array}{l}\text { For: CATGCTGGATGGACACCGT } \\
\text { Rev: CTGTATAGTCCACAGGCCGC }\end{array}$ & 58 & 229 \\
\hline Btk & $\begin{array}{l}\text { For: TGTCCTTCCTCTCTGGACTGTA } \\
\text { Rev: ATGCAGGTAGCTCCCCAGAC }\end{array}$ & 56 & 111 \\
\hline $\mathrm{ABC1}$ & $\begin{array}{l}\text { For GCATTTCCCGAAAGGCAACA } \\
\text { Rev: TCGACTCGTCCCAGATCCTT }\end{array}$ & 57 & 222 \\
\hline Gpr39 & $\begin{array}{l}\text { For: CCCATTGCAAAGAGGGGTGT } \\
\text { Rev: CTCTGGGCCTGTGTTATAGGG }\end{array}$ & 59 & 153 \\
\hline Rgma & $\begin{array}{l}\text { For: CAGCCGCCAAGGGAGGG } \\
\text { Rev: AAGCTGCAGAGAAGGAAGC }\end{array}$ & 56 & 119 \\
\hline Ube4b & $\begin{array}{l}\text { For: GTCACCAGACCGCAATCTCA } \\
\text { Rev: GGCTCCCAAACTAGACAACGA }\end{array}$ & 59 & 109 \\
\hline Ubr1 & $\begin{array}{l}\text { For: CCCTTAAGATGGCGGACGAA } \\
\text { Rev: TGGAACGCTCCACTGTGTTT }\end{array}$ & 58 & 298 \\
\hline Esyt3 & $\begin{array}{l}\text { For: CTCGTGCCTTGAGGACAGATG } \\
\text { Rev: CTGCATCTCGCTGTCGCC }\end{array}$ & 57 & 100 \\
\hline Mical3 3 & $\begin{array}{l}\text { For: TCTCGCTCTTGGCATGGAGCTA } \\
\text { Rev: TCCTTGTCGGATACACTCACT }\end{array}$ & 57 & 106 \\
\hline Dhh & $\begin{array}{l}\text { For: ATGTAGGCAGAGTTAGCGGC } \\
\text { Rev: CGTTCTTGTCCTCACTGGCT }\end{array}$ & 58 & 136 \\
\hline Rragd & $\begin{array}{l}\text { For: GTGAAGCCCAGAATCCTGCT } \\
\text { Rev: CATCCTGGGAGTCGATGACG }\end{array}$ & 59 & 268 \\
\hline C1qutnf4 & $\begin{array}{l}\text { For: ACTCGTCGCCGGCTAAAC } \\
\text { Rev: CACCTTG TCGAAGGTCACCG }\end{array}$ & 60 & 298 \\
\hline Scd1 1 & $\begin{array}{l}\text { For: GAGTACCGCTGGCACATCAA } \\
\text { Rev: AAGCCCAAAGCTCAGCTACTC }\end{array}$ & 60 & 158 \\
\hline Cables1 & $\begin{array}{l}\text { For: GTATATTTTCCGTGCTGCCGT } \\
\text { Rev: TCCACACCTTCAAGGCCAAT }\end{array}$ & 59 & 121 \\
\hline Rcbtb2 & $\begin{array}{l}\text { For: CCCTTCTCCCTAGTCCCAGT } \\
\text { Rev: GATCAGTCCTGTG CAGTCCCC }\end{array}$ & 58 & 277 \\
\hline Txndc16 & $\begin{array}{l}\text { For: GGTGAGCTTCTCAGGTAGGC } \\
\text { Rev:AAGCGATCCAGTTTCCGCTC }\end{array}$ & 59 & 207 \\
\hline Eml4 & $\begin{array}{l}\text { For: CCTGATTAACGCACATTACCCC } \\
\text { Rev: ACGTCAGAGGACTGCAGC }\end{array}$ & 58 & 242 \\
\hline Lhx $x 2$ & $\begin{array}{l}\text { For: ACCTAGCTGTTCCTGGGTGA } \\
\text { Rev: CATCGCTAGCTGGGTTCTGG }\end{array}$ & 57 & 102 \\
\hline Cnih2 & $\begin{array}{l}\text { For: : G TTCACACTTCGCACGATCC } \\
\text { Rev: AAACGCTCGGGGCCC }\end{array}$ & 57 & 157 \\
\hline Btrc & $\begin{array}{l}\text { For: AGAGCAGACCCAGTAGTCCG } \\
\text { Rev: TCCTAGGGGGTTGGCATTA }\end{array}$ & 56 & 229 \\
\hline $\mathrm{Cdc} 25 \mathrm{c}$ & $\begin{array}{l}\text { For: AAGTCCTGAGCTTGCCTGAC } \\
\text { Rev: CATTTTGGGGTTCCTCCCGA }\end{array}$ & 60 & 265 \\
\hline Gpr55 & $\begin{array}{l}\text { For: TGGCTTTTGACACTCGCTGA } \\
\text { Rev: AAATTCCCTGCCCTTTCGCT }\end{array}$ & 60 & 279 \\
\hline Atg4c & $\begin{array}{l}\text { For: TCTACGAATGGCCGGTTCTG } \\
\text { Rev: GCAGAATCGAGAGAGGCTCC }\end{array}$ & 58 & 100 \\
\hline Dnmt3a & For: TTGGAACCCGCCAACTC & 59 & 289 \\
\hline Crtc3 & For: CAAACCCCAGGACCCCTATG & 59 & 220 \\
\hline & $\begin{array}{l}\text { Rev: AACACACACAGGAACGAGGGCC } \\
\text { Forr GGCAAGGAGAACTCTCTCAC }\end{array}$ & & \\
\hline Gimap1 & $\begin{array}{l}\text { For: GGAAAGAAGAACACTCTCACAC } \\
\text { Rev: GCTCATTCCTGAGGCTTCTTG }\end{array}$ & 57 & 101 \\
\hline Kras & $\begin{array}{l}\text { For: AGAACTGGGGAGGGCTTTCT } \\
\text { RevGCACATGTAACACCTGTCT }\end{array}$ & 58 & 248 \\
\hline Arhgap27 & $\begin{array}{l}\text { For: GGTGACT TCCTCCGACAAGG } \\
\text { Rev: GCCACACCTGACTGTCTCCC }\end{array}$ & 58 & 132 \\
\hline uc029rok.1 & For: ACACAGCTTGGATCAGCCTC & 59 & 101 \\
\hline NR_045598.1 & $\begin{array}{l}\text { Rev: GTGCCCAAATGGGAACCCAG } \\
\text { For: TTGTAGAAGGGCCTCGC }\end{array}$ & & 101 \\
\hline & $\begin{array}{l}\text { For: 1TTGTAGAAAGGCCCTCGC } \\
\text { Rev: TCTTGAACTGTGAGCACGCC }\end{array}$ & 59 & 185 \\
\hline ENSMUST00000155906 & $\begin{array}{l}\text { For: GCTTTGCAAACCAGATGGGC } \\
\text { Rev;CCGCTCTACGCTGTTCT }\end{array}$ & 60 & 153 \\
\hline NR_040343.1 & $\begin{array}{l}\text { For: TATCCTCAGAGTGCGGTCCT } \\
\text { Rev: CTGGTGTCCCCAATTCCCAA }\end{array}$ & 59 & 198 \\
\hline uc029rok.1 & 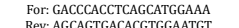 & 58 & 283 \\
\hline AK043175.1 & $\begin{array}{l}\text { For: GGGGAGGCCCAGTTTAAATT } \\
\text { Rev: CCACAGCTTGCCTTGGAGTA }\end{array}$ & 58 & 195 \\
\hline TCONS_00000098 & 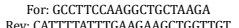 & 60 & 229 \\
\hline ENSMUST00000181641 & $\begin{array}{l}\text { For: CCGCTGGTGTGGGCAGTG } \\
\text { Rev: CGTCAAAAGGTTCCGTCCCT }\end{array}$ & 59 & 124 \\
\hline uc012dts. 1 & $\begin{array}{l}\text { For: GGGCGGGCAGTAAGTGATA } \\
\text { Rev: }\end{array}$ & 59 & 102 \\
\hline ENSMUST00000137134 & $\begin{array}{l}\text { For: ATATCCAGTAAGCAACGCGCG } \\
\text { Rev: TGCTTCCTAGACAGGTCCCA }\end{array}$ & 57 & 134 \\
\hline AK089598.1 & $\begin{array}{l}\text { For: ACAAGTTGGGTTGGGGGAAG } \\
\text { Rev: TCATCCTTCATCCCTCGGGT }\end{array}$ & 57 & 258 \\
\hline ENSMUST00000118407 & $\begin{array}{l}\text { For CCGGTGTTGAGGCCTAATAAC } \\
\text { Rev: CACTGGTTTGGTGCAGAT }\end{array}$ & 58 & 163 \\
\hline ENSMUST00000168470 & $\begin{array}{l}\text { For: GGACAAGCCTACCCACGGAAG } \\
\text { Rev CCTCCACACACACTCACT }\end{array}$ & 59 & 101 \\
\hline ENSMUST00000180860 & $\begin{array}{l}\text { Rev: CCTTCCAACACCCACACCACAT } \\
\text { For GGTGTCAGTAGAGCGGATG } \\
\text { RevG TTCACGATCAGTCACA }\end{array}$ & 59 & 209 \\
\hline uc008hps. 1 & $\begin{array}{l}\text { Reve GTCAGCATCCAGTCCACCA } \\
\text { For: TTCCACACCCACGGATACTG }\end{array}$ & 60 & 277 \\
\hline AK038464.1 & $\begin{array}{l}\text { Rev: GTGTTGGCCTCCATCCATGC } \\
\text { For: AAGCACCCCGATGTTCAC }\end{array}$ & 60 & 238 \\
\hline 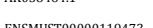 & & 50 & 237 \\
\hline ENSMUST 100000119473 & $\begin{array}{l}\text { For: AGAGGAAGGIGAIGLCGGG } \\
\text { Rev: TCACCTAGGCCAGTGATTGC }\end{array}$ & 59 & 237 \\
\hline AK134149.1 & $\begin{array}{l}\text { For: ACCGCCAGTGAGGTATTCTGC } \\
\text { Rev: TCATCAAAGGGGGCTCTA }\end{array}$ & 58 & 245 \\
\hline АК029865.1 & $\begin{array}{l}\text { For: GAAGACAAGAGGGGTTCGCA } \\
\text { Rev: GTGGGGTGAGGGTACACAAG }\end{array}$ & 57 & 168 \\
\hline AK005751.1. & $\begin{array}{l}\text { For GCCAGGAATTCGCTAACTC } \\
\text { Rev: TCAGGTACATGCCAATGCGT }\end{array}$ & 57 & 114 \\
\hline uc0081хa.2 & For: TGAAGCGCATGAAAAACGCA & 58 & 155 \\
\hline ENSMUST00000154000 & $\begin{array}{l}\text { Rev: CTTTCCCCGGTTGAGGGGGTCC } \\
\text { For: GGAAGGGCAAACAGTGGGAA }\end{array}$ & 58 & 120 \\
\hline AK139441.1 & 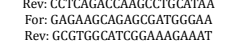 & 59 & 169 \\
\hline ENSMUST00000149226 & $\begin{array}{l}\text { For: TGCTCGAAGCTCTACCTCCT } \\
\text { Rev: CATCTATCGCCCCCCCCC }\end{array}$ & 59 & 220 \\
\hline ENSMUST00000117590 & $\begin{array}{l}\text { Rev: CATCTATTGGCCCCACCCCCC } \\
\text { For: ATCTGGGGGTAGCCAAAAA } \\
\text { Rev: AAGGAACCGTGAGTCTTCCAG }\end{array}$ & 60 & 173 \\
\hline AK007117.1 & $\begin{array}{l}\text { For: CCCTAGGAGGCGGGGTATAG } \\
\text { ReV ACGAGGGGGTCGGAT }\end{array}$ & 59 & 123 \\
\hline uc009ape.1 & 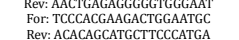 & 60 & 279 \\
\hline uc012dts 1 & 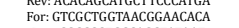 & 58 & 141 \\
\hline & 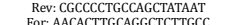 & & 141 \\
\hline uc.70- & $\begin{array}{l}\text { For: AAACACTGCAGGGCTCTGGCC } \\
\text { Rev: GAGATCTCAGGCACTGTC }\end{array}$ & 59 & 152 \\
\hline uc056ywo.1 1 & $\begin{array}{l}\text { For: CGGGATTCATGCTTCTGCCT } \\
\text { Rev GCCATTCCTTGATCCTTGA }\end{array}$ & 57 & 207 \\
\hline ENSMUST00000181777 & 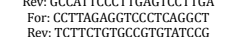 & 58 & 197 \\
\hline
\end{tabular}


http://www.kegg.jp// was utilized to confirm pathway enrichment. The $p$-value was used to indicate the significance of the pathway, and the lower of the $p$-value, the higher the significance of the pathway.

\section{CNC analysis}

CNC analysis was performed by calculating the Pearson correlation coefficient (PCC) between the expression levels of coding and noncoding genes. We initially selected the DE IncRNAs and mRNAs from microarray data, and the expressions of these molecules in ESP-induced macrophages and M1 macrophages were respectively confirmed by qPCR. Based on the qPCR results and the PCC value (PCC $\geq 0.995$ and $P<$ 0.05 ) between the IncRNA and mRNA, the co-expression network was built and illustrated using Cytoscape (v3.4.0). In the network, the value of interaction represented the likelihood that the two genes were coexpressed. Higher values indicated stronger interaction, and the degree value represented the number of interacting genes. Furthermore, higher degrees suggested higher likelihood of centrality location of the mRNA or IncRNA in the network. Analyses were performed by KangChen Bio-tech, Shanghai, China.

\section{Construction of ceRNA networks}

IncRNAs or mRNAs can interact with miRNAs through their MicroRNA Recognition Elements (MREs) within a ceRNA network. The ceRNA network was constructed as follows: we initially selected the DE IncRNAs and mRNAs in microarray data, and the expressions of these molecules in ESP-induced macrophages and M1 macrophages were comfirmed by qPCR, respectively. Based on the qPCR results and the screening parameter (fold change of $\geq 2.0$ and $P$ value $<0.05$ ), the dysregulated IncRNA or mRNA was used to perform miRNA target prediction using the latest miRBase, which collects abundant miRNAs and is extensively used as miRNA reference [41-43]. The obtained miRNAs were screened by miRanda and TargetScan programs. LncRNAs or mRNAs that possessed the MREs of targeted miRNAs were predicted by RNA22 (https:// cm.jefferson.edu/rna22/Precomputed/) and PITA (http:// genie.weizmann.ac.il/pubs/mir07/mir07_data. $\mathrm{html}$ ). The ceRNA network was built and illustrated by using Cytoscape (v3.4.0). Analyses were performed by KangChen Bio-tech, Shanghai, China.

\section{Statistical analysis}

Numerical data were analyzed by software SPSS Statistics 17.0 (SPSS Inc.) using the two-tailed Student's $t$ - test, ANOVA, and the Mann-Whitney test. All data were presented as the mean \pm standard error of the mean (SEM). Spearman correlation was used to determine the relationship between IncRNAs and their target genes. An absolute fold change $\geq 2, P<0.05$ was used to screen differentially expressed IncRNA and mRNA. $P<0.05$ was considered statistically significant.

\section{Results}

Differentially expressed IncRNAs and mRNAs in ESP-induced M2 cells compared to polarized M1 cells

Peritoneal macrophages from F. gigantica ESP-injected BALB/c mice were isolated, and the phenotypes were identified by PCR and qPCR using phenotype-specific primers. Fig. $1 \mathrm{~A}$ shows that all three M2 phenotypic molecular markers resulted in positive amplification (Fig. 1A (a)), thereby suggesting successful induction of ESP-mediated M2 cells. Western blotting and qPCR assay further verified stronger M2 phenotype was induced by F. gigantica ESP and the phenotype was successfully switched into M1 macrophage (Fig. 1A (b, c)). Furthermore, ELISA results showed that ESP-stimulated M2 macrophages secreted higher levels of IL10 and low IL12 than M1 cells, and upon IFN $\gamma+$ LPS-induced M2 to M1 polarization, lower levels of IL10 and increased IL12 secretion were observed (Fig. 1A (d)). To explore the dysregulated IncRNAs and mRNAs during IFN $\gamma+$ LPS-induced polarization from M2 to M1 macrophages, we determined the IncRNA and mRNA expression profiles using microarray analyses of M2 and M1 macrophages. Heatmaps, scatter plots, and volcano plots were used to assess variations in IncRNA expression between M1 and M2 cells (Figs. 1B-G). All lncRNAs and mRNAs showing a two-fold change in signal intensity ( $\mathrm{p}$ value $<0.05$ ) were identified as differentially expressed when the M1 subtype was compared to the M2 cells. In total, 35, 667 
Fig. 1. Differentially expressed lncRNAs in F. gigantica ESPinduced M2 macrophages compared with polarized M1 macrophages. (A) Identification of the phenotype of F. gigantica ESPinduced macrophages. a. PCR identification of ESP-induced macrophages and the macrophages re-induced by IFN $\gamma+$ LPS. The molecules YM1, RELM $\alpha$ and Arginase-1 were used as markers for M2 phenotype, while iNOS was as M1 phenotype. b, Western blotting of the F. gigantica ESP-induced macrophages and the macrophages re-induced by IFN $\gamma+$ LPS. c, qPCR assay of the $F$. gigantica ESP-induced macrophages and the macrophages re-induced by IFN $\gamma+$ LPS. Three duplicated wells of each phenotype of macrophage were collected for qPCR assay ( $\mathrm{n}=3$ ). d. ELISA assay of the F. gigantica ESP-induced macrophages and the macrophages re-induced by IFN $\gamma+L P S$. IL10 represents M2 macrophage cytokine, while IL12 represents M1 macrophage cytokine. (B and C) Differentially expressed lncRNAs (B) and mRNAs (C) between F. gigantica ESP-induced M2 macrophages and IFN $\gamma+\mathrm{LPS}$ re-induced M1 macrophages were analyzed using hierarchical clustering; Three parallel samples in each group were analyzed. 'red' indicates high expression, and 'green' indicates low expression. (D and E) A scatter plot is used to assess lncRNA (D) and mRNA (E) expression variations between F. gigantica ESP-induced M2 macrophages and polarized M1 macrophages. IncRNAs and mRNAs above the top green line and below the green line exhibited a greater than 2.0-fold changes. ( $F$ and G) A volcano plot is used to assess lncRNA (F) and mRNA (G) expression variations between F. gigantica ESP-induced M2 macrophages and polarized M1 macrophages. Red plots represent differentially expressed lncRNAs and mRNAs. 
Fig. 2. Statistics of IncRNAs, mRNAs and UCRs obtained during the differentiation from F. gigantica ESPinduced M2 to polarized M1 phenotype macrophages. (A) and (B)Total numbers of lncRNAs, mRNAs and UCRs, and differentially expressed lncRNAs, mRNAs and UCRswere presented, respectively. (C. D. E. F) Six types of IncRNAs and UCRs were found in total and differentially expressed lncRNAs (C and D) and UCRs (E and F), respectively. Only those fold changes $>2.0$ and $\mathrm{p}<0.05$ were count as differentially expressed genes. (G) Heatmap of UCRs obtained during macrophage differentiation.
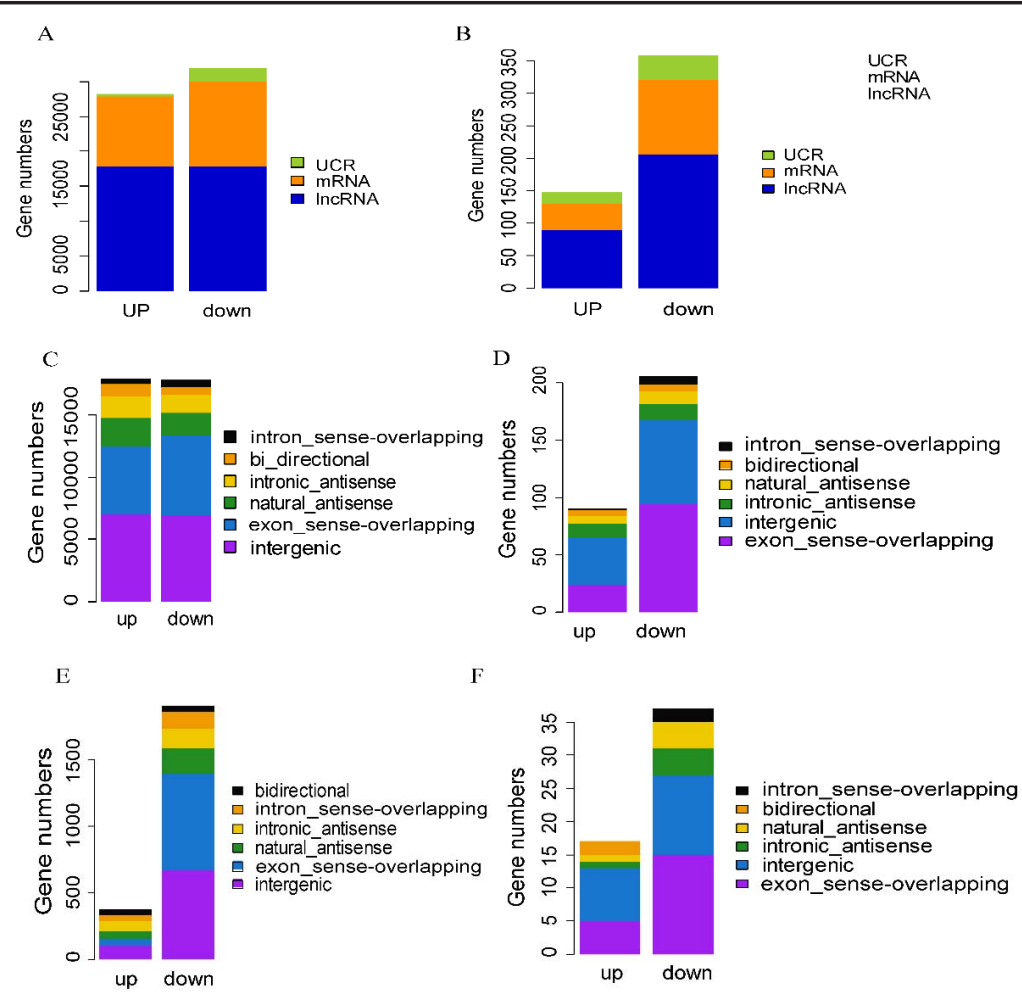

F

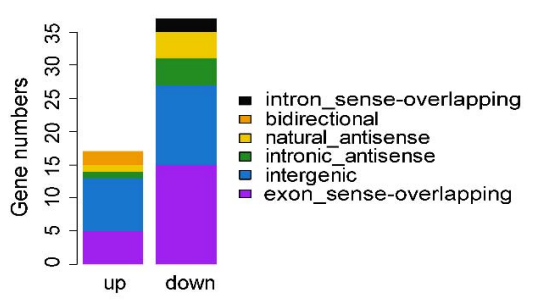

G

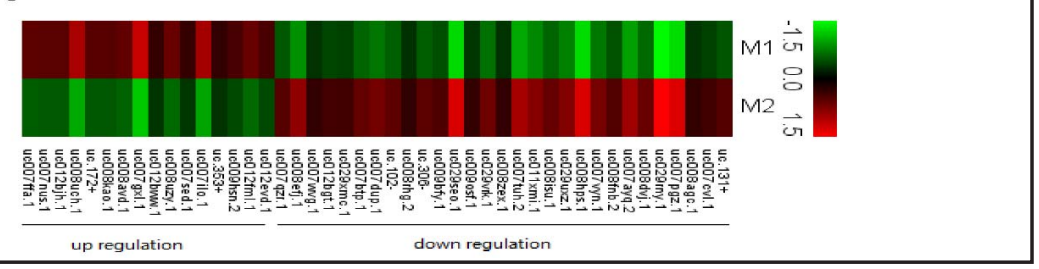

IncRNAs and 22, 201 mRNAs were obtained (Figs. 2 A, B), and among these, 2, 844 lncRNAs and 1, 782 mRNAs were differentially expressed (Figs. 2 A, B). In the differentially expressed lncRNAs, 1, 579 transcripts were upregulated and 1, 265 transcripts were downregulated. Furthermore, 789 and 993 mRNAs were up- and downregulated, respectively (Figs. 2 A, B). In particular, one type of IncRNAs, known as ultra-conserved RNAs (UCRs), was observed during macrophage polarization. Figures 2 A, B, and G show that a total of 243 UCRs were differentially expressed, of which 52 were upregulated and 191 were downregulated. In total, six types of lncRNAs and UCRs were identified during polarization (Figs. 2 C-F). The upand downregulated lncRNAs (absolute fold change $\geq 2$ ) identified in the microarray analyses are presented in Table 1 and 2.

\section{Validation of the microarray data by $q P C R$}

qPCR analysis was performed to verify the reliability of the microarray results, and the expression levels of randomly selected 34 lncRNAs and mRNAs in ESP-induced M2 and polarized M1 macrophages were detected. All primers are presented in Table 3. The qPCR results indicated that 30 transcripts out of 34 selected genes were positively amplified, of which 20 were used in generating the Pearson correlation coefficient (PCC) in M1 and M2 macrophages. Fig. 3 A shows the 12 transcripts (Ch25h, Ube4b, Rragd, Scd1, Gpr55, Btk, ENSMST00000154000, ENSMST00000117590, ENSMST00000168470, ak043175.1, uc0008hps.1, and ENSMST00000118407) that were verified by the qPCR assay and coincided with the PCC results ( $r=0.726$ in M1 and $r=0.684$ in M2) between the qPCR value and the microarray results in both M1 and M2 cells (Fig. 3 B). 


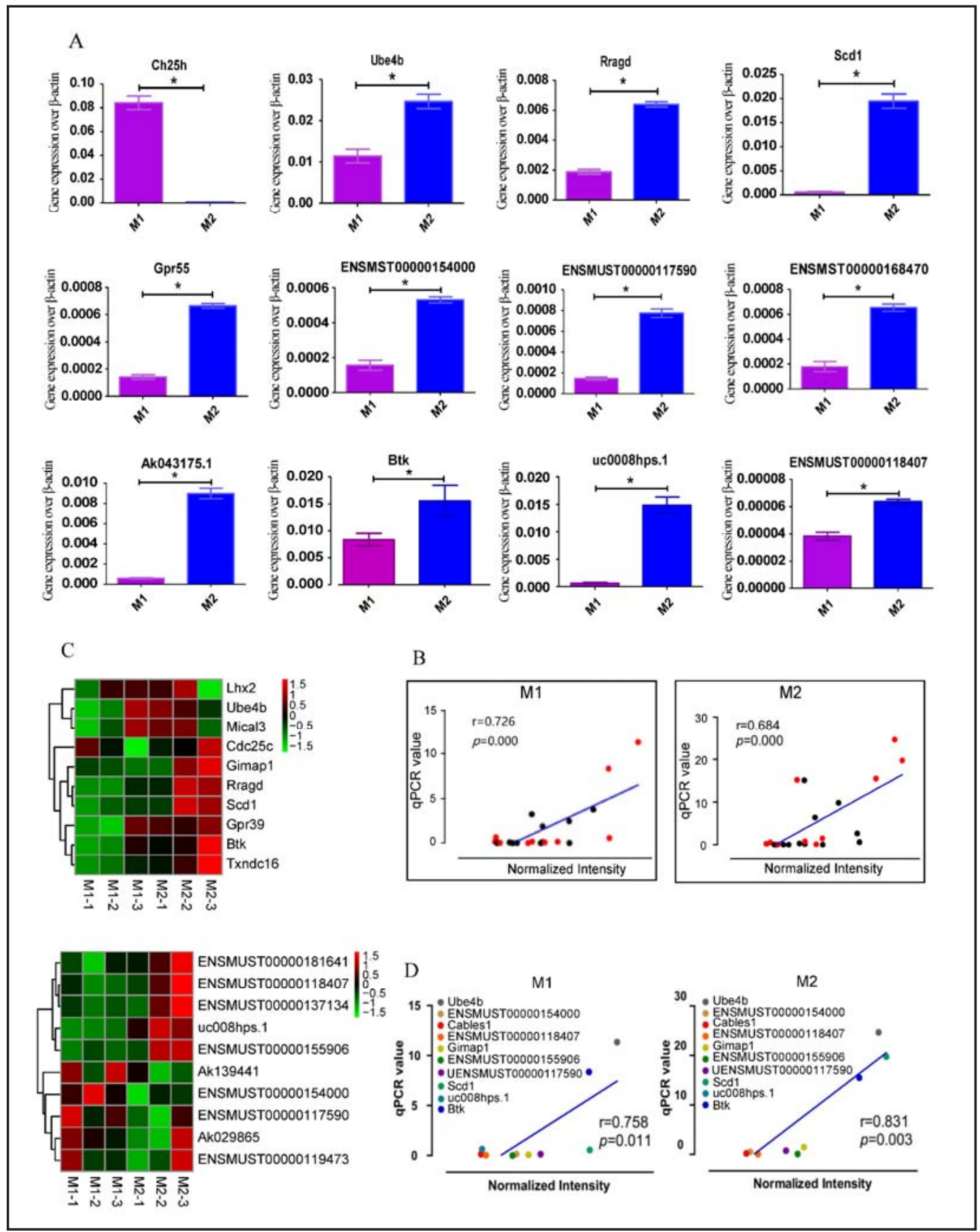

Fig. 3. QPCR validation of candidate lncRNAs and mRNAs among F. gigantica ESP-induced M2 macrophages and the polarized M1 macrophages. The relative expression levels of 34 candidate lncRNAs and mRNAs were detected by qPCR in ESP-induced M2 macrophages and the polarized M1 macrophages. The $\Delta \mathrm{Ct}$ values of the lncRNAs and mRNAs were determined by subtracting the $\beta$-actin $\Delta \mathrm{Ct}$ value. A smaller $\Delta \mathrm{Ct}$ value is, the higher expression level indicates. (A)Twelve lncRNAs and mRNAs were presented to represent the results of qPCR validation. * indicates $\mathrm{p}<0.05$. Three duplicated wells of each phenotype of macrophage were collected for qPCR assay ( $n=3$ ). (B) Ten lncRNAs and mRNAs in M1 and M2 macrophages, respectively were selected randomly to evaluate the relationship of microarray results and qPCR value which was analyzed by Spearman's coefcients. (C) Heatmaps of nine picked lncRNAs and their neighboring mRNAs, and (D) presented their relationships analyzed by Spearman's coefcients. 
The correlation of IncRNAs and associated coding genes

Previous studies have indicated that lncRNAs can affect the expression of neighboring protein-coding genes. Based on the UCSC database (http://genome.ucsc.edu/), our microarray provided data on nearby protein-coding genes (Tables 1 and 2). To investigate the association between IncRNA expression and associated protein-coding genes, we randomly selected 10 paired lncRNAs and mRNAs for qPCR and PCC analyses. Figures 3 C and D show that the expression profiles of the 10 paired IncRNAs and mRNAs were positively correlated $(p<0.05)$, and the correlation index was 0.758 in M1 and 0.831 in M2, respectively, thereby indicating good consistency between qPCR values and the microarray results in both the M1 and M2 cells.

\section{Bioinformatic analysis of differentially expressed IncRNAs}

To explore the potential functions and mechanism of the lncRNAs during polarization from M2 to M1 macrophages, we conducted GO and pathway analyses for the target genes of the differentially expressed IncRNAs. The biological process (Figs. 4 A, B), molecular function

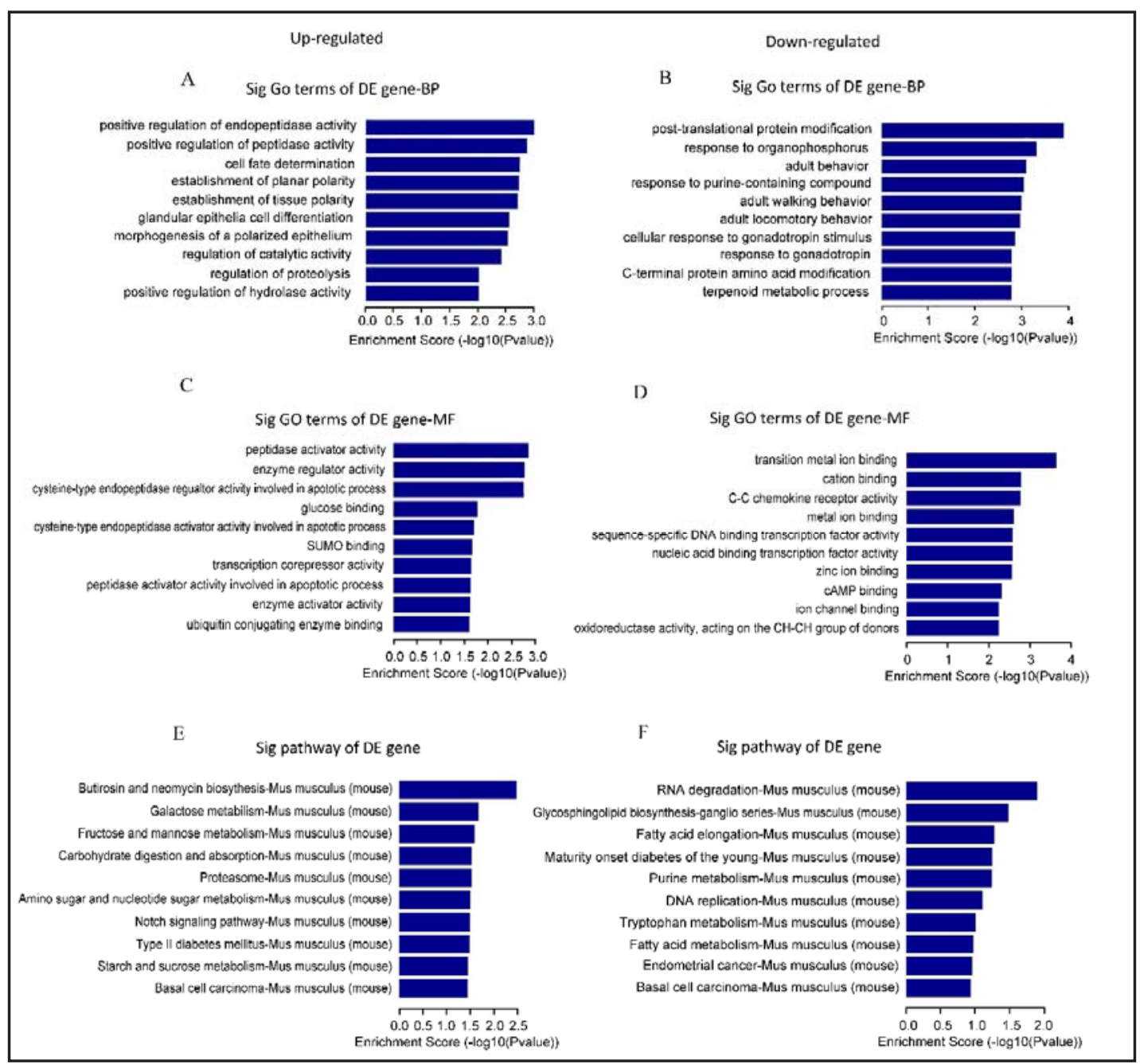

Fig. 4. GO analysis and pathway analysis of the differentially expressed lncRNAs. Top ten GO terms of biological processes (A and B) and molecular function (C and D) for IncRNAs upregulated and downregulated during the differentiation from F. gigantica ESP-induced M2 to polarized M1 phenotype macrophages. (E and F) Top ten pathways corresponding to the IncRNAs upregulated and downregulated during the differentiation from F. gigantica ESP-induced M2 to polarized M1 phenotype macrophages. 
(Figs. 4 C, D), and cellular component (unpublished) were predicted by the GO Project. Biological processes revealed that the associated protein-codinggene functions of upregulated lncRNAs (M1 vs. M2) were primarily involved in positive regulation of endopeptidase and peptidase activity, cell fate determination, and establishment of planar polarity (Fig. 4 A). In addition, the associated protein-coding gene function of the downregulated lncRNAs primarily included post-translational protein modification, response to organophosphorus, adult behavior, and response to purine-containing compounds (Fig. 4 B). In terms of molecular function, the genes of upregulated lncRNAs primarily included peptidase activator activity, enzyme regular activity, cysteine-type endopeptidase regulator activity involved in apoptotic process, and glucose binding. The genes of downregulated lncRNAs were primarily involved in transition metal ion binding, cation binding, C-C chemokine receptor activity, and metal ion binding. Pathway analysis showed that these gene products were involved in several signaling pathways. Regarding the upregulated transcripts (M1 vs. M2), the major pathways included butirosin and neomycin biosynthesis, galactose metabolism, fructose and mannose metabolism, and carbohydrate digestion and the absorption signaling pathway (Fig. 4 E). The downregulated transcripts were mainly involved in RNA degradation, glycosphingolipid biosynthesis (ganglio series), fatty acid elongation, and the maturity onset diabetes of the young signaling pathway (Fig. 4 F).

Fig. 5. Coding and non-coding gene (CNC) network example of the IncRNA and mRNA. Totally eight significantly expressed IncRNAs and mRNAs were conducted to build the CNC network. (A) represented the CNC network of two mRNAs and (B) represented the $\mathrm{CNC}$ network of IncRNAs. In each network, dozens of mRNAs or IncRNAs were connected. The value of interaction represents the likelihood that the two genes are coexpressed. The bigger of the valve, the stronger of the interaction. The degree value represents the number of genes that can interact with. The higher the degree, the more centrally the mRNA or IncRNA locates in the network.

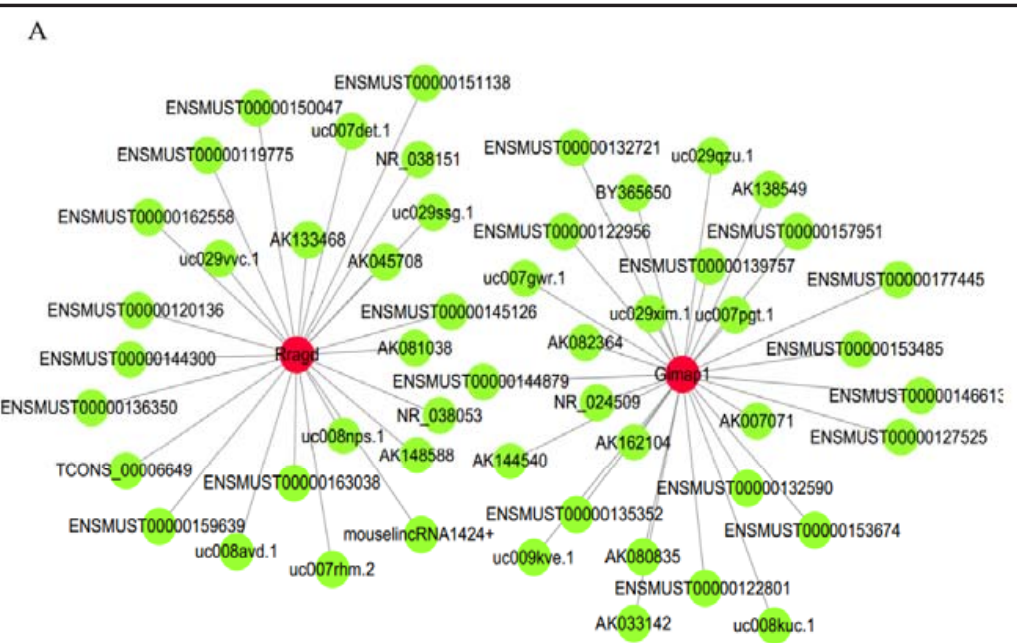

B

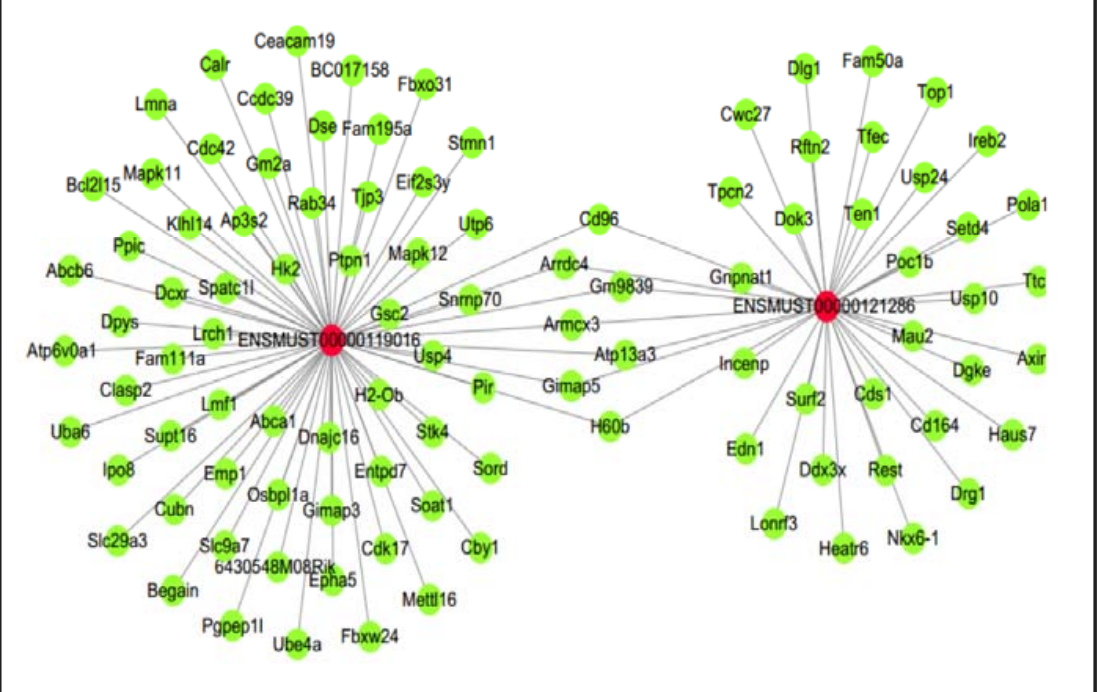




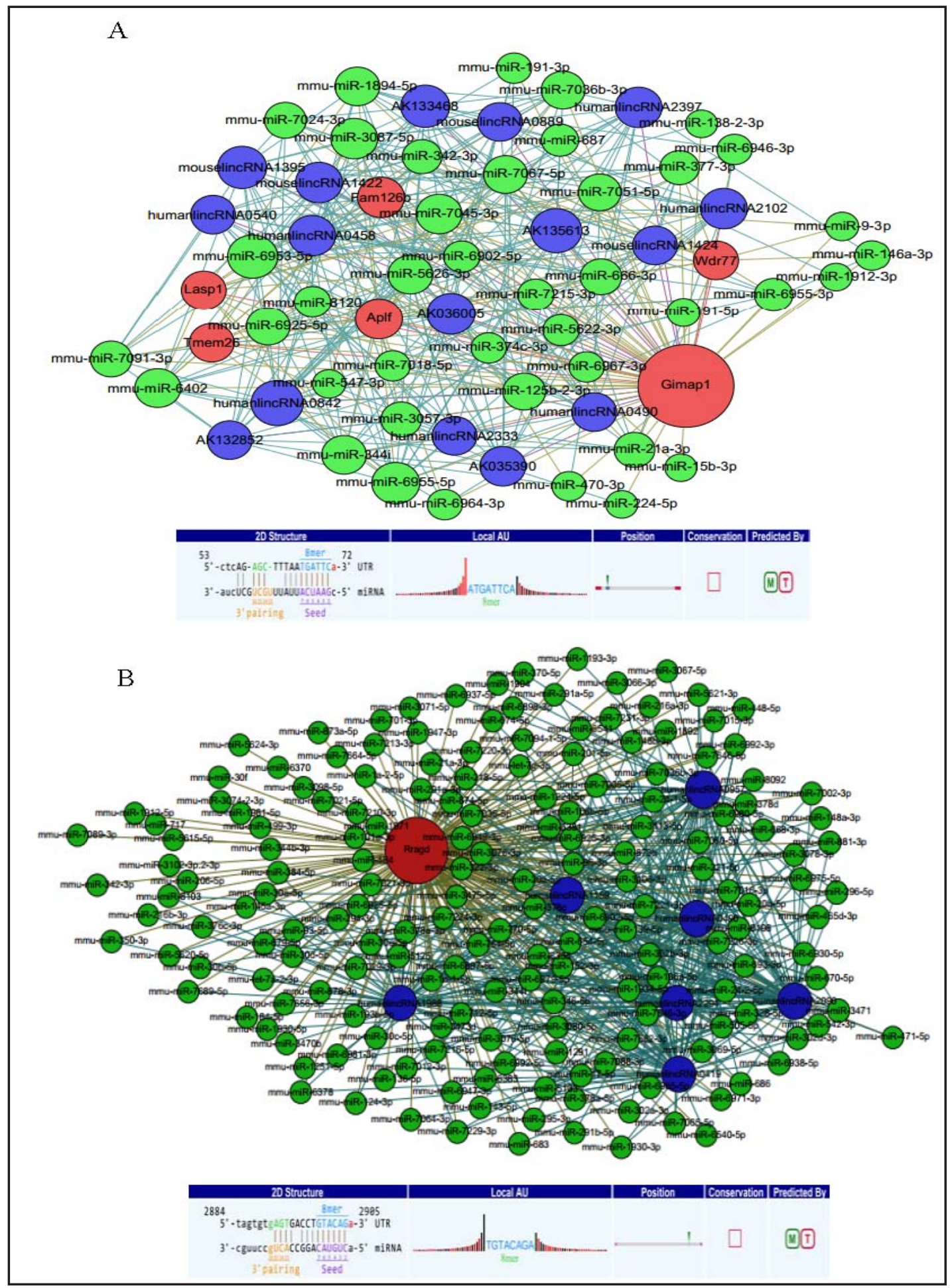

Fig. 6. CeRNA network example during the differentiation from F. gigantica ESP-induced M2 to polarized M1 phenotype macrophages. (A) Differentially expressed Gimap1 was picked to build its ceRNA network including 41 microRNA targets that interact with Gimap1. The picture below the network showed an example of the MicroRNA Recognition Elements (MRE) that recognized Giamp1. (B) Differentially expressed Rragd was picked to build its ceRNA network including 180 microRNA targets that interact with Rragd. The picture below the network showed an example of the MRE that recognized Rragd. Red circle represents mRNAs, blue circle represents lncRNAs and green circle represents miRNAs that involved in ceRNA network. 


\section{Coding and non-coding gene (CNC) analysis}

To explore the relationship of coding mRNA and its non-coding genes, we performed the CNC analysis by calculating the PCC between the expression levels of coding and non-coding genes. In total, eight differentially expressed mRNAs and IncRNAs were selected, and the coexpression network was built and illustrated using Cytoscape (v3.4.0). As shown in Fig. 5 A, two mRNA and two lncRNAs were used to illustrate CNC relationship. Rragd had 24 while Gimap1 had 28 differentially expressed lncRNAs, as indicated by statistically significant $p$ values. Among these, 16 and 13 genes were downregulated, and 8 and 15 were upregulated, corresponding to Rragd and Gimap, respectively. The other two selected mRNAs, Btk and Scd1, had 55 and 130 differentially expressed lncRNAs, respectively (unpublished). For lncRNAs, ENSMUST00000119016 and ENSMUST00000121286 were selected to show their relationships with corresponding mRNAs (Fig. 5 B), and had 24 and 28 differentially expressed mRNAs based on the $p$ value, respectively. The other two selected lncRNAs, ENSMUST00000143435 and human lincRNA1907, had 55 and 130 differentially expressed mRNAs, respectively (unpublished).

\section{Construction of competing endogenous RNAs (ceRNA) network}

Because mRNAs and IncRNAs can interact with miRNAs through their MREs within a ceRNA network [17], we initially selected four mRNAs based on qPCR validation results and searched for putative MREs of Gimap1, Rragd, Scd1, and Btk by RNA22 and PITA analyses. As shown in Fig. 6 A, a total of 38 lncRNAs, 8 mRNAs, and 41 miRNAs were predicted to be involved in the Gimap1 ceRNA networks. CK375702, AK135613, mouselincRNA1395+, and AK133468 were the top four lncRNAs with the highest number of MREs shared with ceRNA and Gimap1. Moreover, 41 miRNA binding sites were shared with ceRNA and Gimap1. For each miRNA, 1 to 6 MREs were found to bind to Gimap1, respectively. Two examples of the MREs binding site are shown in Figs. 6 A, B, in which there were eight MREs in seed sequences. The ceRNA networks of Rragd included 7 lncRNAs and 180 miRNAs (Fig. 6 B). In total, 180 MREs were shared with ceRNA and Rragd. HumanlincRNA0957-, humanlincRNA0490-, humanlincRNA2090+, and humanlincRNA1159- were the top four lncRNAs with the highest number of MREs that were shared between ceRNA and Rragd. For each miRNA, 1 to 4 MREs were found to bind to Rragd, respectively. We further conducted ceRNA network for Scd1 and Btk and found that 34 lncRNAs and 192 miRNAs were involved in the Scd1 ceRNA network, while 241 lncRNA, 65 mRNAs, and 47 miRNAs were involved in the Btk ceRNA network (unpublished).

\section{Discussion}

Fasciola ESP-induced M2 cells exhibit common immunobiological features $[5,6]$. Previous studies have examined Fasciola ESP- induced M2 macrophage polarization in mice and human $[18,19]$. In the current study, our objective was to identify potential lncRNAs and mRNAs that might be novel targets for preventive, diagnostic or therapeutic strategies against fasciola infections. We hypothesized that the identification of molecular targets that can regulate the M1 and M2 switching, may be important in discovering ways in which F.gigantica infections may be controled by genetic engineering. LncRNAs have been shown to play important roles in macrophage polarization and activation [14-16]; therefore, we explored whether IncRNAs extended this function to F. gigantica ESP-induced macrophage polarization. In our study, immunological reactions in which mice responded to ESP stimulation in vivo were simulated, and we detected the differentially expressed lncRNAs and mRNAs in F. gigantica ESP-induced M2 cells and compared these with IFN- $\gamma+$ LPS-induced M1 cells. Our data showed that some lncRNAs and their target genes significantly increased or decreased during the phenotype switching, suggesting our strategy was meaningful. To the best of our knowledge, this is the first report on lncRNA expression profiling in $F$. gigantica ESP-induced M2 polarization into M1 cells, providing clues in the elucidation of the mechanism of helminth-induced M2 regulation in helminth-related microenvironment. 
Compared to protein-coding genes, IncRNAs exhibit spatio-temporal specific expression profiling, which makes lncRNAs a promising molecular tool for decoding biological processspecific mechanisms. For example, lncRNAs were found to be highly dynamic and showed cell-specific expression patterns during T cell polarization. Specifically, LncR-Ccr2-5'AS, together with GATA-3, is essential in the regulatory circuit in gene expression specific to the migration of Th2 cells [20]. Such roles of lncRNAs were also found in CD8 ${ }^{+} \mathrm{T}$ cell [21] and $\mathrm{CD}^{+} \mathrm{T}$ cell polarization $[22,23]$. More importantly, lncRNAs also play essential roles on macrophage polarization. For instance, knocking down TCONS_00019715 following the activation of THP- 1 cells using IFN- $\gamma$ and LPS diminished the expression of M1 markers and elevated the expression of M2 markers [16]. Another lncRNA, lnc-MC, acted as a ceRNA to miR-199a-5p and alleviated repression of activin A receptor type 1B (ACVR1B), a regulator of monocyte/macrophage polarization [14]. In our study, 1, 579 and 1, 265 lncRNAs and 789 and 993 mRNAs were upregulated and downregulated, respectively, in Fasciola ESPinduced M2 cells differentiated into IFN- $\gamma$ + LPS-induced M1 cells. Among the lncRNAs, 52 upregulated and 191 downregulated UCRs were differentially expressed. We compared these UCRs with human T-UCRs, and found that five UCRs (uc.172, uc.352, uc.101, uc.131, and uc.306) were expressed in both human T-UCRs and our database, suggesting these UCRs are conserved and may be important for macrophage polarization. This indicated that lncRNAs indeed play essential roles on the biological process of Fasciola ESP-induced M2 cells polarization into M1 cells.

To select lncRNAs and mRNAs that play important roles in Fasciola ESP-induced M2 cells polarization into M1 cells, differentially expressed lncRNAs and mRNAs between Fasciola ESP-induced M2 cells and IFN- $\gamma+$ LPS-induced M1 cells were selected and used in validating the microarray results with qPCR analysis. Our qPCR results indicated that most of the IncRNA and mRNA expression profiles coincided with the microarray results, and were further supported by the CNC profiling results. The results of the CNC analysis and qPCR assays consistently revealed that lncRNAs play roles during M2 cell polarization into M1 cells. Our results, to some extent, are also consistent with those of Huang et al [16].. However, because no lncRNAs patterns during helminths ESP- induced macrophages polarization have been reported to date, we cannot directly compare our data to those of Huang et al., and thus we are unable to elucidate common underlying mechanisms. In addition, the objective of our study differed from theirs. Our aim was to investigate lncRNA profiles during macrophage polarization from ESP-induced M2 to M1 (M1 vs. M2), whereas the data from Huang et al. examined lncRNA expression during macrophage polarization from M0 to M1 and M2 (M1 vs. M0, M2 vs. M0, M2 vs. M1). Moreover, the major difference in both studies are the stimulators. In the present study, the ESP was used to induce the M2 phenotype, whereas the IL4 was used by Huang et al. Furthermore, we obtained M2 macrophages in vivo, that is because only the real physiological and immunological conditions can represent the real immunological reactions in which mice respond to ESP stimulation. Therefore, the lncRNAs produced in both studies during the biological process were different. Because macrophages are quite plastic cells, it is quite possible that different lncRNAs are produced in different immunological conditions.

Our qPCR results showed that some mRNAs such as Rragd, Scd1, Gimap1, and Btk show good PCC relationship with their corresponding lncRNAs, including ENSMUST00000119473, uc008hps.1, ENSMUST00000155906, and ENSMUST00000117590. This finding suggests that differentially expressed mRNAs and IncRNAs may be co-regulated by certain networks. We therefore investigated the functions of Rragd, Scd1, Gimap1, and Btk. Rragd (Ras-related GTPbinding D) that might be involved in transmitting signals within macrophages. Ras-regulated signalling pathways control processes such as cell proliferation, polarization, adhesion, and migration. Scd1 (stearoyl-coenzyme A desaturase 1) is the rate-limiting enzyme in the synthesis of monounsaturated fatty acids. Nakaya et al. reported that macrophage-specific SCD1 overexpression promoted overall reverse cholesterol transport through increased cholesterol efflux of high-density lipoproteins [24]. Gimap1 (GTPase, IMAP family member 1) has been suggested as essential for the development of mature B and T lymphocytes [25]

\section{KARGER}


and its expression in human T cell may vary under Th1 or Th2 polarization conditions in vitro [26]. Btk (bruton agammaglobulinemia tyrosine kinase) has been reported to regulate macrophage polarization in response to LPS [27]. Furthermore, Feng et al. demonstrated that macrophages express calreticulin and that TLR signaling through Btk results in its trafficking to the cell surface, where it induces macrophage-mediated programmed removal of tumor cells [28]. Given these genes functionally act in macrophages and their corresponding lncRNAs co-regulate with them in some networks, these lncRNAs may logically play crucial roles in macrophage polarization, and thus contribute to helminth-induced immunological progresses in which macrophages play essential roles. Although gain-of-function and lossof-function experiments on these lncRNAs and mRNAs were not been performed in this study, their expression patterns in M1 and M2 cells provide clues that they may be crucial in the regulation of $\mathrm{M} 2$ or $\mathrm{M} 1$ polarization.

A large number of lncRNAs were identified in our study. However, the functions of these lncRNAs remain unclear. To infer the possible functional roles of the lncRNAs between $F$. gigantica ESP-induced M2 cells and IFN- $\gamma$ + LPS-induced M1 cells, GO and pathway analyses were initially used for the functional analysis of the lncRNA target gene pool. GO analysis revealed that differentially expressed IncRNAs were most highly enriched in "regulation of peptidase activity", "metabolism", and "post-translational protein modification". Moreover, pathway analysis indicated that "galactose metabolism", "fructose and mannose metabolism", "carbohydrate digestion and absorption signaling pathway", "glycosphingolipid biosynthesis", and "fatty acid elongation" were involved in the processes of $F$. gigantica ESP-induced M2 polarization into M1 cells. Therefore, it is reasonable to infer that these differentially expressed lncRNAs act mainly by regulating the peptidase activity and carbohydrate metabolism, which in turn affects the regulation of peptidase activity and metabolism of macrophages. Moreover, lncRNAs have been well known to regulate cell cycle progression, imprinting, cell polarization, and development in response to cellular and/or developmental signals [29]. However, whether IncRNAs are involved in peptidase activity and carbohydrate metabolism remains unclear. Nonetheless, some studies have reported that IncRNAs can regulate carbohydrate metabolism progression in cancers. For instance, lncRNA GCASPC regulate glycolysis in cancer cells by directly binding with key glycolytic enzymes [30] and lncRNA NRCP is an intermediate binding partner between STAT1 and RNA polymerase II, leading to increased expression of glucose-6-phosphate isomerase [31]. Zhao et al. reported that LINC00092 interacts with 6-phosphofructo-2-kinase/fructose-2, 6-biphosphatase 2 (PFKFB2) and is involved in increased glycolysis levels in ovarian cancer metastasis [32]. Moreover, GAL IncRNAs (galactose-related gene in budding yeast Saccharomyces cerevisiae) promote induction from a repressed state that could have biological relevance to galactose metabolic adaptation [33]. Although no lncRNA studies have been reported on the regulation of peptidase activity and carbohydrate metabolism in macrophages or even parasite ESPinduced macrophage polarization, our current study provides evidence that ESP-induced IncRNAs could regulate macrophage polarization by modulating peptidase activity and/or carbohydrate metabolism, which may be meaningful in the elucidation of a new mechanism underlying parasite-induced macrophage phenotype differentiation.

Increasing literatures have confirmed that ceRNAs play key roles in many biological processes and immune responses [34,35], and miRNAs have been documented to be involved in the regulation of macrophage polarization [36, 37] , similar to lncRNAs [14-16]. We were interested in identifying whether an mRNA-related ceRNA network existed during F. gigantica ESP-induced M2 cell polarization into M1 cells. We selected four differentially expressed mRNAs (Gimap1, Rragd, Scd1, and Btk) and built respective ceRNA networks since these mRNAs were identified and confirmed by qPCR and CNC analyses We found that almost three types of RNAs were included in each ceRNA network, implying a complicated regulation network modulate each mRNA. Given that these mRNAs play essential roles on ESP-induced macrophage polarization, lncRNAs and miRNAs might also play regulatory roles during this differentiation process. Although we did not confirm the functions of the IncRNAs and miRNAs in our study, we found that some miRNAs in the ceRNA network were possibly involved in

\section{KARGER}


macrophage function. For example, miR-6955-5p, miR-6953-5p, and miR-1894-5p were the top three miRNAs of Gimap1 and miR-3076-5p, miR-346-5p, and miR-6381 were the top three miRNAs of Rragd, all of which have more than 4 binding sites on their corresponding mRNAs, thus may likely function as "molecular sponges" that compete with corresponding IncRNAs. CeRNAs have been widely implicated in various biological processes, and studies have confirmed that disorders involving the ceRNA network can induce tumorigenesis [38]. Although ceRNA has not been reported in parasite ESP-induced macrophage polarization, ceRNA may be involved in M2 macrophage differentiation. Nevertheless, the ceRNA network presented in this study highlights an unknown ceRNA regulatory network in ESP-induced macrophage polarization.

Although our work is the first report on IncRNA profiling in F. gigantica ESP-induced M2 polarization into M1 cells, we realize that some limitations should be addressed. One such shortcoming might be the lack of large number of lncRNA candidates that have been identified as therapeutic targets, thus comparisons are incomplete. Another weakness might be the non-deep verification of the ceRNAs regulatory networks due to lack of specific cell lines and animal models. Nonetheless, we believe that these limitations will be addressed in our future studies focusing on the functions and therapeutic potentials of the discovered lncRNAs and mRNAs in the present study.

\section{Acknowledgements}

This work was supported by the National Science Foundation of China (Grant No., 81160262) and the Science Foundation of Guangxi (Grant No., 2011GXNSFD018032, GK2013-13-B 01 and 141240034). We thank LetPub (www.Letpub.com) for its linguistic assistance during the preparation of this manuscript.

Honglin Luo designed and coordinated the study, analyzed the data, and wrote the manuscript. Yaoyao Zhang performed cell culture and qPCR identification. Zhaoan Sheng participated in qPCR identification and data preparation. Tao Luo, Jie Chen and Junjie Liu developed the methodologies for cell culture, bioinformatics analysis, and mouse keeping. Huifeng Wang, Miao Chen and Yunliang Shi collected experimental materials and analyzed the data. Lequn Li conceived the study, drafted the manuscript, and provided crucial advice on data analysis. All authors read and approved the manuscript.

\section{Disclosure Statement}

The authors declare to have no conflict of interests.

\section{References}

1 Mills CD: M1 and M2 Macrophages: Oracles of Health and Disease. Criti Rev in immunol 2012;32:463-488.

-2 Sica A, Mantovani A: Macrophage plasticity and polarization: in vivo veritas. J Clin Invest 2012;122:787795.

-3 Gordon S, Martinez FO: Alternative activation of macrophages: mechanism and functions. Immunity 2010;32:593-604.

4 Van Dyken SJ, Locksley RM: Interleukin-4- and interleukin-13-mediated alternatively activated macrophages: roles in homeostasis and disease. Annu Rev Immunol 2013;31:317-343.

-5 Cortes A, Munoz-Antoli C, Esteban JG, Toledo R: Th2 and Th1 Responses: Clear and Hidden Sides of Immunity Against Intestinal Helminths. Trends Parasitol 2017;33:678-693.

6 Adams PN, Aldridge A, Vukman KV, Donnelly S, O’Neill SM: Fasciola hepatica tegumental antigens indirectly induce an M2 macrophage-like phenotype in vivo. Parasite immunol 2014;36:531-539. 


\section{Cellular Physiology Cell Physiol Biochem 2018;47:505-522

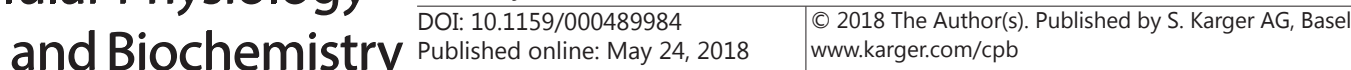

Luo et al.: LncRNA Profiling of ESP-Induced Macrophages

7 Flynn RJ, Irwin JA, Olivier M, Sekiya M, Dalton JP, Mulcahy G: Alternative activation of ruminant macrophages by Fasciola hepatica. Vet Immunol Immunopathol 2007;120:31-40.

8 Furst T, Keiser J, Utzinger J: Global burden of human food-borne trematodiasis: a systematic review and meta-analysis. Lancet Infect Dis 2012;12:210-221.

-9 Bargues MD, Gayo V, Sanchis J, Artigas P, Khoubbane M, Birriel S, Mas-Coma S: DNA multigene characterization of Fasciola hepatica and Lymnaea neotropica and its fascioliasis transmission capacity in Uruguay, with historical correlation, human report review and infection risk analysis. PLoS Negl Dis 2017;11:e0005352.

-10 Machicado C, Machicado JD, Maco V, Terashima A, Marcos LA: Association of Fasciola hepatica Infection with Liver Fibrosis, Cirrhosis, and Cancer: A Systematic Review. PLoS Negl Dis 2016;10:e0004962.

11 Chen JX, Chen MX, Ai L, Xu XN, Jiao JM, Zhu TJ, Su HY, Zang W, Luo JJ, Guo YH, Lv S, Zhou XN: An Outbreak of Human Fascioliasis gigantica in Southwest China. PloS One 2013;8:e71520.

12 Nagano T, Fraser P: No-nonsense functions for long noncoding RNAs. Cell 2011;145:178-181.

13 Batista PJ, Chang HY: Long noncoding RNAs: cellular address codes in development and disease. Cell 2013;152:1298-1307.

14 Chen MT, Lin HS, Shen C, Ma YN, Wang F, Zhao HL, Yu J, Zhang JW: PU.1-Regulated Long Noncoding RNA lncMC Controls Human Monocyte/Macrophage Differentiation through Interaction with MicroRNA 199a-5p. Mol Cell Biol 2015;35:3212-3224.

15 Reddy MA, Chen Z, Park JT, Wang M, Lanting L, Zhang Q, Bhatt K, Leung A, Wu X, Putta S, Saetrom P, Devaraj S, Natarajan R: Regulation of inflammatory phenotype in macrophages by a diabetes-induced long noncoding RNA. Diabetes 2014;63:4249-4261.

16 Huang Z, Luo Q, Yao F, Qing C, Ye J, Deng Y, Li J: Identification of Differentially Expressed Long Non-coding RNAs in Polarized Macrophages. Sci Rep 2016;6:19705.

-17 Salmena L, Poliseno L, Tay Y, Kats L, Pandolfi PP: A ceRNA hypothesis: the Rosetta Stone of a hidden RNA language? Cell 2011;146:353-358.

18 Zawistowska-Deniziak A, Basalaj K, Strojny B, Mlocicki D: New Data on Human Macrophages Polarization by Hymenolepis diminuta Tapeworm-An In Vitro Study. Front Immunol 2017;8:148.

19 Moreno Y, Gros PP, Tam M, Segura M, Valanparambil R, Geary TG, Stevenson MM: Proteomic analysis of excretory-secretory products of Heligmosomoides polygyrus assessed with next-generation sequencing transcriptomic information. PLoS Negl Dis 2011;5:e1370.

20 Hu G, Tang Q, Sharma S, Yu F, Escobar TM, Muljo SA, Zhu J, Zhao K: Expression and regulation of intergenic long noncoding RNAs during T cell development and differentiation. Nat Immunol 2013;14:1190-1198.

21 Pang KC, Dinger ME, Mercer TR, Malquori L, Grimmond SM, Chen W, Mattick JS: Genome-wide identification of long noncoding RNAs in CD8+ T cells. J Immunol 2009;182:7738-7748.

22 Guttman M, Amit I, Garber M, French C, Lin MF, Feldser D, Huarte M, Zuk O, Carey BW, Cassady JP, Cabili MN, Jaenisch R, Mikkelsen TS, Jacks T, Hacohen N, Bernstein BE, Kellis M, Regev A, Rinn JL, Lander ES: Chromatin signature reveals over a thousand highly conserved large non-coding RNAs in mammals. Nature 2009;458:223-227.

23 Pagani M, Rossetti G, Panzeri I, de Candia P, Bonnal RJ, Rossi RL, Geginat J, Abrignani S: Role of microRNAs and long-non-coding RNAs in CD4(+) T-cell differentiation. Immunol Rev 2013;253:82-96.

-24 Nakaya K, Ayaori M, Uto-Kondo H, Sotherden GM, Nishida T, Katamoto H, Miura Y, Takiguchi S, Yakushiji E, Iizuka M, Ogura M, Sasaki M, Yogo M, Komatsu T, Adachi T, Maruyama C, Ikewaki K: Overexpression of stearoyl-coenzyme A desaturase 1 in macrophages promotes reverse cholesterol transport. Biochim Biophys Acta 2013;1831:1402-1411.

25 Saunders A, Webb LM, Janas ML, Hutchings A, Pascall J, Carter C, Pugh N, Morgan G, Turner M, Butcher GW: Putative GTPase GIMAP1 is critical for the development of mature B and T lymphocytes. Blood 2010;115:3249-3257.

-26 Filen JJ, Filen S, Moulder R, Tuomela S, Ahlfors H, West A, Kouvonen P, Kantola S, Bjorkman M, Katajamaa M, Rasool O, Nyman TA, Lahesmaa R: Quantitative proteomics reveals GIMAP family proteins 1 and 4 to be differentially regulated during human T helper cell differentiation. Mol Cell Proteomics : MCP 2009;8:3244.

27 Ni Gabhann J, Hams E, Smith S, Wynne C, Byrne JC, Brennan K, Spence S, Kissenpfennig A, Johnston JA, Fallon PG, Jefferies CA: Btk regulates macrophage polarization in response to lipopolysaccharide. PloS One 2014;9:e85834. 


\section{Cellular Physiology Cell Physiol Biochem 2018;47:505-522 \begin{tabular}{l|l} 
and Biochemistry Published onlIne:IMay 24, 2018 & $\begin{array}{l}\text { DO } 2018 \text { The Author(s). Published by S. Karger AG, Basel } \\
\text { www.karger.com/cpb }\end{array}$ \\
\hline
\end{tabular}}

Luo et al.: LncRNA Profiling of ESP-Induced Macrophages

-28 Feng M, Chen JY, Weissman-Tsukamoto R, Volkmer JP, Ho PY, McKenna KM, Cheshier S, Zhang M, Guo N, Gip P, Mitra SS, Weissman IL: Macrophages eat cancer cells using their own calreticulin as a guide: roles of TLR and Btk. Proc Natl Acad Sci U S A 2015;112:2145-2150.

29 Rinn JL, Chang HY: Genome regulation by long noncoding RNAs. Annual Rev Biochem 2012;81:145-166.

-30 Ma MZ, Zhang Y, Weng MZ, Wang SH, Hu Y, Hou ZY, Qin YY, Gong W, Zhang YJ, Kong X, Wang JD, Quan ZW: Long Noncoding RNA GCASPC, a Target of miR-17-3p, Negatively Regulates Pyruvate CarboxylaseDependent Cell Proliferation in Gallbladder Cancer. Cancer Res 2016;76:5361-5371.

-31 Rupaimoole R, Lee J, Haemmerle M, Ling H, Previs RA, Pradeep S, Wu SY, Ivan C, Ferracin M, Dennison JB, Millward NM, Nagaraja AS, Gharpure KM, McGuire M, Sam N, Armaiz-Pena GN, Sadaoui NC, RodriguezAguayo C, Calin GA, Drapkin RI, Kovacs J, Mills GB, Zhang W, Lopez-Berestein G, Bhattacharya PK, Sood AK: Long Noncoding RNA Ceruloplasmin Promotes Cancer Growth by Altering Glycolysis. Cell Rep 2015;13:2395-2402.

32 Zhao L, Ji G, Le X, Wang C, Xu L, Feng M, Zhang Y, Yang H, Xuan Y, Yang Y, Lei L, Yang Q Lau WB, Lau B, Chen Y, Deng X, Yao S, Yi T, Zhao X, Wei Y, Zhou S: Long Noncoding RNA LINC00092 Acts in Cancer-Associated Fibroblasts to Drive Glycolysis and Progression of Ovarian Cancer. Cancer Res 2017;77:1369-1382.

-33 Cloutier SC, Wang S, Ma WK, Al Husini N, Dhoondia Z, Ansari A, Pascuzzi PE, Tran EJ: Regulated Formation of IncRNA-DNA Hybrids Enables Faster Transcriptional Induction and Environmental Adaptation. Mol Cell 2016;61:393-404.

-34 Wang H, Huo X, Yang XR, He J, Cheng L, Wang N, Deng X, Jin H, Wang C, Zhao F, Fang J, Yao M, Fan J, Qin W: STAT3-mediated upregulation of IncRNA HOXD-AS1 as a ceRNA facilitates liver cancer metastasis by regulating SOX4. Mol Cancer 2017;16:136.

35 Lai K, Jia S, Yu S, Luo J, He Y: Genome-wide analysis of aberrantly expressed lncRNAs and miRNAs with associated co-expression and ceRNA networks in beta-thalassemia and hereditary persistence of fetal hemoglobin. Oncotarget 2017;8:49931-49943.

-36 Roy S: miRNA in Macrophage Development and Function. Antioxid Redox Signal 2016;25:795-804.

-37 He X, Tang R, Sun Y, Wang YG, Zhen KY, Zhang DM, Pan WQ: MicroR-146 blocks the activation of M1 macrophage by targeting signal transducer and activator of transcription 1 in hepatic schistosomiasis. EBioMedicine 2016;13:339-347.

38 Dai Q Li J, Zhou K, Liang T: Competing endogenous RNA: A novel posttranscriptional regulatory dimension associated with the progression of cancer. Oncol Lett 2015;10:2683-2690.

-39 El Ridi R, Salah M, Wagih A, William H, Tallima H, El Shafie MH, Abdel Khalek T, El Amir A, Abo Ammou FF, Motawi H: Fasciola gigantica excretory-secretory products for immunodiagnosis and prevention of sheep fasciolosis. Vet Parasitol 2007;149:219-228.

40 Layoun A, Samba M, Santos MM: Isolation of murine peritoneal macrophages to carry out gene expression analysis upon Toll-like receptors stimulation. J Vis Exp 2015:e52749.

-41 Lu MH, Tang B, Zeng S, Hu CJ, Xie R, Wu YY, Wang SM, He FT, Yang SM: Long noncoding RNA BC032469, a novel competing endogenous RNA, upregulates hTERT expression by sponging miR-1207-5p and promotes proliferation in gastric cancer. Oncogene 2016;35:3524-3534.

\$2 Liu Q, Hu X, Zhang X, Dai L, Duan X, Zhou C, Ao Y: The TMSB4 Pseudogene LncRNA Functions as a Competing Endogenous RNA to Promote Cartilage Degradation in Human Osteoarthritis. Mol Ther 2016;24:1726-1733.

43 Huang M, Zhong Z, Lv M, Shu J, Tian Q, Chen J: Comprehensive analysis of differentially expressed profiles of IncRNAs and circRNAs with associated co-expression and ceRNA networks in bladder carcinoma. Oncotarget 2016;7:47186-47200. 